\title{
Acute Charcot foot
}

\author{
Piero Baglioni physician in endocrinology and diabetes ${ }^{1}$, Manzar Malik consultant radiologist ${ }^{2}$, \\ Onyebuchi E Okosieme consultant physician in endocrinology and diabetes ${ }^{1}$
}

${ }^{1}$ Department of Endocrinology and Diabetes, Prince Charles Hospital, Cwm Taf Local Health Board, Merthyr Tydfil CF47 9DT, UK; ${ }^{2}$ Department of Radiology, Prince Charles Hospital

This is one of a series of occasional articles highlighting conditions that may be more common than many doctors realise or may be missed at first presentation. The series advisers are Anthony Harnden, university lecturer in general practice, Department of Primary Health Care, University of Oxford, and Richard Lehman, general practitioner, Banbury. To suggest a topic for this series, please email us at easilymissed@bmj.com

A 38 year old man was referred by his general practitioner to our diabetes foot clinic with a swollen red foot (fig $1 \Downarrow$ ). He had had type 1 diabetes for 25 years, complicated with retinopathy, peripheral neuropathy, and nephropathy, and was being worked up for dialysis following a failed pancreas-kidney transplant. The absence of pain together with preserved pulses and intact skin raised a suspicion of acute Charcot foot. A plain radiograph of the foot showed fractures through the necks of the first three metatarsals (fig $2 \Downarrow$ ). We offloaded the foot in a total contact cast and advised the patient to limit weight bearing. Magnetic resonance imaging (MRI) subsequently confirmed neuroarthropathic changes of acute Charcot (fig $3 \Downarrow$ ).

\section{What is acute Charcot foot?}

Charcot's neuroarthropathy is a destructive process of bone and joint, typically seen in a foot that has lost its protective sensory innervation. The classic description of this disabling condition by Jean-Martin Charcot in 1883 was in patients with tabes dorsalis, but nowadays most cases of Charcot foot occur as a complication of diabetes mellitus. The chronic stage of the disease is easily recognisable, but the acute phase can present a diagnostic challenge. ${ }^{1}$ In a recent series the diagnosis of acute Charcot foot was missed before specialist referral in 19 of 20 patients. ${ }^{2}$ In another report, referring clinicians failed to diagnose Charcot foot in 19 of 24 cases seen in a specialist diabetes foot clinic. $^{3}$

\section{Why is acute Charcot foot missed?}

The acute phase of a Charcot foot may not be considered or may be mistaken for more common causes of leg or foot swelling, such as cellulitis, gout, deep venous thrombosis, or sprains. ${ }^{2}$ The misdiagnosis of ankle sprain is particularly common if the patient recalls a history of trivial injury. Standard radiographs may show no abnormalities at this stage, contributing to delays in diagnosis. ${ }^{3}$

\section{Why does this matter?}

The delay in correct diagnosis is harmful because during the acute phase the foot bones are vulnerable to fragmentation and dislocation. ${ }^{1}$ If the patient continues to walk on an insensitive foot, this may lead-sometimes within weeks-to irreversible deformities, such as mid-foot dislocation or collapse and inversion of the plantar arch, the so called rocker-bottom foot. These deformities may, in turn, predispose to skin ulcer, an established risk factor for amputation. ${ }^{4}$ If the disease is diagnosed in the acute phase, bone and joint damage can largely be prevented by avoiding weight bearing. ${ }^{1}$ Timely recognition may also identify patients with diabetes who are at increased risk of mortality owing to the severe neuropathy associated with Charcot foot. ${ }^{5}$ In one series, patients with acute Charcot foot or neuropathic foot ulcers had a 5-year mortality rate of $40 \% .^{5}$ Mortality may relate to co-existent renal disease in some patients, but neuropathy is also believed to independently increase cardiovascular risk by promoting vascular calcification. ${ }^{6}$

\section{How is acute Charcot foot diagnosed? Clinical features}

The usual presentation is a red, swollen, warm foot in which pulses are preserved (fig 1). Owing to neuropathy, pain is not always present or is less than expected for the severity of the clinical findings. Longstanding diabetes, either type 1 or type 2 , or a history of renal transplantation confer a particularly high risk. $^{7}$ The patient may be thought at this stage to have gout, ankle sprain, or deep venous thrombosis, but the most common misdiagnosis is infection. The presence of an ulcer favours the diagnosis of cellulitis or osteomyelitis, particularly if this can be probed to bone. Absence of skin break, stable insulin 


\section{Key points}

- Suspect acute Charcot foot in a patient with diabetes and neuropathy who presents with a swollen warm foot

- If acute Charcot foot is suspected, arrange for offloading of the foot (to minimise further damage) and refer to a specialist foot clinic immediately

- Plain radiographs may be normal in the early stages of the disease

- Magnetic resonance imaging should be considered when the suspicion of acute Charcot foot is high

\section{How common is acute Charcot foot?}

- The true incidence of acute Charcot foot is difficult to establish, because few population based studies have been published and no diagnostic criteria have been universally agreed

- The reported annual incidence of Charcot arthropathy in patients with diabetes has varied from $0.3 \%$ in population studies ${ }^{11}$ to $12.0 \%$ in referral centre studies ${ }^{7}$

- Studies in specialist units report that Charcot arthropathy was present in $9 \%$ of patients with diabetic neuropathy and foot ulcer ${ }^{12}$ and in $12 \%$ of diabetic patients who had received pancreas-kidney transplants

requirements, and normal white blood cell counts or $\mathrm{C}$-reactive protein levels are more suggestive of acute Charcot than infection. ${ }^{8}$ Neuro-arthropathy and infection are, however, not mutually exclusive and if any doubt exists the patient should be treated for both conditions until the true diagnosis is established. ${ }^{8}$

\section{Investigations}

Standard radiographs are an important first line investigation. The finding of fractures or bony misalignment in the absence of obvious trauma is highly suggestive of Charcot foot (fig 2). The initial radiograph may be normal, but this should not divert from the diagnosis if the clinical suspicion is high. ${ }^{3} \mathrm{~A}$ radioisotope bone scan or MRI can show bone disease even when radiographic changes are subtle (fig 3 ). The choice between nuclear imaging and MRI is largely based on local availability and experience. ${ }^{9}$ Bone scan has less specificity than MRI (25-38\% v80-100\%), but the diagnostic sensitivity of either test approaches $100 \% .^{10}$ The mid-foot region is the most common site of disease, although hind-foot involvement carries a particularly severe prognosis owing to the risk of ankle instability. MRI is the investigation of choice in patients with ulcers and a high probability of deep infection. However, the differentiation of Charcot from osteomyelitis may occasionally be difficult even with MRI. ${ }^{9} 10$

\section{How is acute Charcot foot managed?}

If acute Charcot foot is suspected, seek urgent referral to a specialist foot clinic and advise patients to avoid weight bearing pending evaluation ${ }^{8}$ Early offloading of the foot with total contact casting is the gold standard of treatment. ${ }^{9}$ Casting is usually needed for three to six months, and healing is indicated by resolution of oedema and warmth. Radiographic or MRI evidence of healing assists the clinical decision to discontinue casting and transfer the patient into a bespoke shoe. ${ }^{9}$ A lifelong programme of patient education and routine foot care should form an essential component of treatment. Reconstructive surgery is currently reserved for patients in whom attempts at conservative care have failed to prevent major deformities. Earlier surgical intervention could nonetheless be considered for patients with ankle disease owing to the often limited success of conservative measures in this form of disease. ${ }^{9}$

Bisphosphonates have been proposed to counteract the excess bone turnover that characterises the acute Charcot foot, but the evidence for their benefit is still inconclusive. ${ }^{9}$

Contributors: PB had the original idea for the paper and wrote the first draft of the paper. All authors contributed to the planning, drafting, and revision of the paper and all approved the final version of the paper. OEO is the guarantor.

Competing interests: All authors have completed the Unified Competing Interest form at www.icmje.org/coi_disclosure.pdf (available on request from the corresponding author) and declare: no support from any organisation for the submitted work; no financial relationships with any organisations that might have an interest in the submitted work in the previous three years; no other relationships or activities that could appear to have influenced the submitted work.

Provenance and peer review: Not commissioned; externally peer reviewed.

Patient consent obtained.

1. Hartemann-Heurtier A, Van GH, Grimaldi A. The Charcot foot. Lancet 2002;360:1776-9.

2 Wukich DK, Sung W, Wipf SA, Armstrong DG. The consequences of complacency: managing the effects of unrecognized Charcot feet. Diabet Med 2011;28:195-8. Chantelau $E$. The perils of procrastination: effects of early vs delayed detection and treatment of incipient Charcot fracture. Diabet Med 2005;22:1707-12.

4 Sohn MW, Stuck RM, Pinzur M, Lee TA, Budiman-Mak E. Lower-extremity amputation risk after charcot arthropathy and diabetic foot ulcer. Diabetes Care 2010;33:98-100.

5 Van Baal J, Hubbard R, Game F, Jeffcoate W. Mortality associated with acute Charcot foot and neuropathic foot ulceration. Diabetes Care 2010;33:1086-9.

6 Jeffcoate WJ, Rasmussen LM, Hofbauer LC, Game FL. Medial arterial calcification in diabetes and its relationship to neuropathy. Diabetologia 2009;52:2478-88.

7 Matricali GA, Bammens B, Kuypers D, Flour M, Mathieu C. High rate of Charcot foot attacks early after simultaneous pancreas-kidney transplantation. Transplantation 2007;83:245-6.

8 Edmonds M, Foster AVM, Sanders LJ. Charcot foot. In: A practical manual of diabetic foot care. 2nd ed. Blackwell Publishing, 2008:63-78

9 Rogers LC, Frykberg RG, Armstrong DG, Boulton AJ, Edmonds M, Van GH, et al. The Charcot foot in diabetes. Diabetes Care 2011;34:2123-9.

10 Rogers LC, Bevilacqua NJ. Imaging of the Charcot foot. Clin Podiatr Med Surg 2008;25:263-74.

11 Fabrin J, Larsen K, Holstein PE. Long-term follow-up in diabetic Charcot feet with spontaneous onset. Diabetes Care 2000;23:796-800.

12 Cavanagh PR, Young MJ, Adams JE, Vickers KL, Boulton AJ. Radiographic abnormalities in the feet of patients with diabetic neuropathy. Diabetes Care 1994;17:201-9.

Cite this as: BMJ 2012;344:e1397

๑ B BMJ Publishing Group Ltd 2012 


\section{Figures}

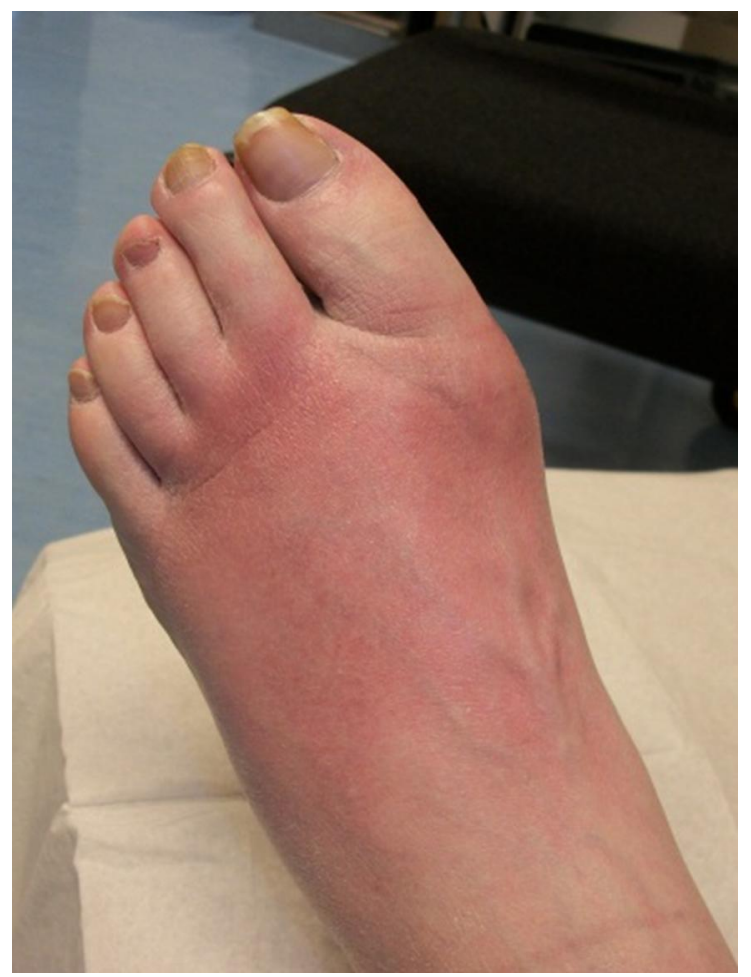

Fig 1 Acute Charcot foot

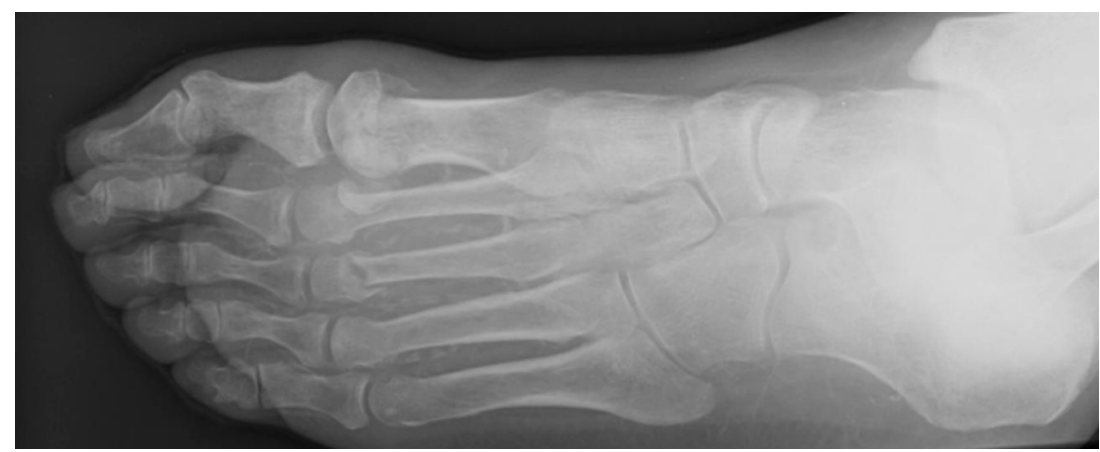

Fig 2 Plain radiograph of the foot showing fractures through the necks of the first three metatarsals 


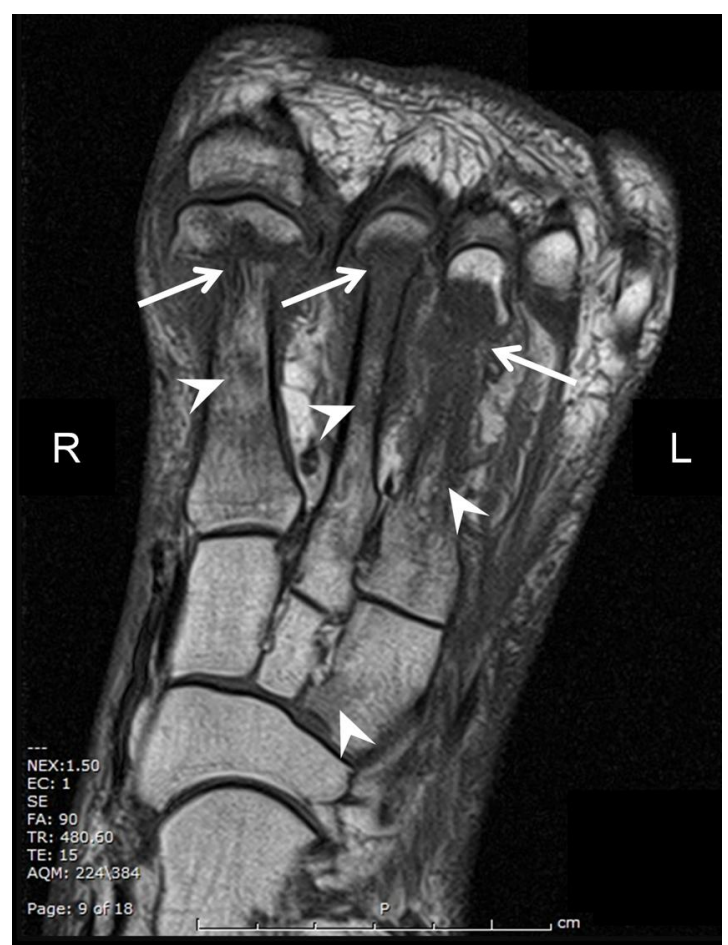

Fig 3 Axial T1 weighted MRI showing pathological fractures through the necks of the first three metatarsals (arrows) with oedema in metatarsal shafts and lateral cuneiform bones (arrow heads). These features, in a patient with diabetes and no history of trauma, suggest acute Charcot foot 